\title{
FORMAÇÃO CONTINUADA VIRTUAL DE PROFESSORES NO ENSINO SUPERIOR: EM FOCO AS COMUNIDADES DE PRÁTICA
}

Sandra Letícia Schroeder Iglesias ${ }^{1}$, Maria Luisa Furlan Costa ${ }^{1}$, Silvana Aparecida Guietti ${ }^{1}$, Patrícia L.L. Mertzig Gonçalves de Oliveira².

${ }^{1}$ Universidade Estadual de Maringá - UEM, Maringá, PR. ${ }^{2}$ Universidade do Oeste Paulista - UNOESTE, Presidente Prudente, SP. E-mail: sandraletigle@hotmail.com

\section{RESUMO}

Este artigo discute o papel das Comunidades de Prática (CoP) virtuais na formação continuada de professores no Ensino Superior. A Lei de Diretrizes e Bases Nacionais no 9.394/96 estabeleceu a formação docente dividida em duas etapas: a inicial e a continuada, assim como sinalizou a utilização das Tecnologias da Informação e da Comunicação (TIC) nos processos formativos. Entende-se que dessa legislação decorre-se diversas experiências de formação continuada de professores utilizando as CoP. O estudo foi desenvolvido por meio da pesquisa bibliográfica. Inicialmente focaliza-se a aprendizagem pautada na participação ativa dos sujeitos. Na sequência, discute-se o conceito de CoP virtual, e, por fim, articula-se a formação continuada de professores por meio das CoP.

Palavras-chave: Formação Continuada, Comunidades de Prática, Ensino Superior.

\section{VIRTUAL CONTINUOUS EDUCATION OF TEACHERS IN HIGHER EDUCATION: IN FOCUS THE COMMUNITIES OF PRACTICE}

\begin{abstract}
This article discusses the role of Virtual Communities of Practice (CoP) in the continuing education of teachers in Higher Education. The National Guidelines and Bases Law No. 9.394 / 96 established the teacher training divided into two stages: initial and continuing, as well as signaling the use of Information and Communication Technologies (ICT) in the formative processes. It is understood that this legislation is followed by several experiences of continuing teacher formation using the CoP. The study was developed through bibliographic research. Initially, the focus is on learning based on the active participation of the subjects. In the sequence, the concept of virtual CoP is discussed, and, finally, we articulates the continuous formation of teachers through the CoP.
\end{abstract}

Keywords: Continuing Education, Communities of Practice, Higher Education. 


\section{INTRODUÇÃO}

No Brasil, a discussão sobre a formação de professores para atuarem no Ensino Superior está amparada na Lei de Diretrizes e Bases da Educação Nacional - LDBEN no 9.394/96 - e explicitada pelo Artigo 66, o qual determina que "a preparação para o exercício do magistério superior far-se-á em de pós-graduação, prioritariamente em programas de mestrado ou doutorado" (BRASIL, 1996, p. 72). Observa-se que a referida Lei não traz outras orientações para esse nível de ensino, porém aponta a necessidade da formação permanente dos profissionais da educação. Nesse sentido, compreende-se que a formação continuada de docentes do Ensino Superior carecem de um movimento de pesquisas mais amplo para atender às novas exigências da sociedade e valorizar a importância do conhecimento no fazer pedagógico.

Nesse contexto, pode-se mencionar a contribuição da Teoria Social da Aprendizagem criada por Jean Lave e Etienne Wenger (1991). Essa Teoria situa a aprendizagem como participação entre as perspectivas que enfatizam a ação e as que enfatizam a estrutura. Lave e Wenger (1991, p. 13) defendem que é "por meio dessas ações e interações locais, que a aprendizagem reproduz e transforma a estrutura social na qual ocorre". Wenger (1998) menciona que nessa perspectiva, desloca-se o enfoque cartesiano e fragmentado do processo de ensino clássico para centralizar os objetivos na aprendizagem como participação social. Assim, essa Teoria pode ser aproximada e ou aplicada a contextos para além dos espaços presenciais de formação e se beneficiar com a aplicação de tecnologias.

Com base na Teoria Social da aprendizagem, salienta-se a necessidade de se trabalhar nas escolas e nas universidades com uma variedade de métodos, técnicas e recursos que proporcionem uma participação mais ativa do aprendente. Nessa direção, propõe-se, primeiramente, repensar a formação docente, a qual na atualidade pode ser realizada também por meio das Tecnologias da Informação e da Comunicação (TIC).

Assim, o Grupo de Pesquisa Educação a Distância e as Tecnologias Educacionais/CNPQ da Universidade Estadual de Maringá (UEM) estuda, dentre outras, temáticas relacionadas a metodologias que utilizam diferentes suportes tecnológicos virtuais que podem colaborar com a formação continuada de professores via CoP, como é o caso desta pesquisa, ampliando dessa forma as possibilidades de desenvolvimento, autonomia e melhores condições de trabalho de professores da educação superior deste país.

\section{METODOLOGIA}

Este estudo caracteriza-se como aprofundamento bibliográfico recorrendo ao posicionamento epistemológico de autores clássicos e contemporâneos. Os descritores selecionados: formação de professores, comunidades de prática e formação virtual indicaram referências teóricas. Entre as principais autores encontram-se Freitas (1997) que trata da formação de professores, Bakhtin (2000) que aborda uso da TIC na formação de professores; Lave e Wenger (1991) com formação continuada virtual e as proposições da Teoria da Cognição Situada; Vygotsky (1989) que fundamenta a concepção de aprendizagem na perspectiva interacionista e Moser (2010) com a formação docente em comunidades de prática. 0 recorte temporal traz a experiência realizada entre 2004 e 2005 e os autores selecionados subsidiaram as reflexões sobre as CoP como possibilidade de formação continuada de professores no Ensino Superior.

\section{RESULTADOS}

A formação docente continuada virtual em exercício encontra respaldo na LDBEN no 9394/96, de 20/12/1996, especificamente no capítulo VI, artigo 62, quando faz referências ao uso das TIC. O artigo 62 traz a seguinte orientação: 
$\S 1$ 을 A união, o Distrito Federal, os estados e os municípios, em regime de colaboração, deverão promover a formação inicial, a continuada e a capacitação dos profissionais de magistério.

§ 20 A formação continuada e a capacitação dos profissionais de magistério poderão utilizar recursos e tecnologias de educação a distância (BRASIL, 1996, p. 22).

Portanto, recorrer às tecnologias existentes como auxílio para a realização de formação continuada em exercício dos professores brasileiros no formato de CoP pode possibilitar uma abrangência maior de participantes, além de uma formação que busca uma ação ativa do professor, fundamentada na experiência de vivenciar a tensão crítica entre teoria e prática (FREITAS, 1997), visto que essa tensão se dá no sujeito e na relação com o outro.

No tocante à formação humana, Habermas (1982 apud FRANCO, 2008, p. 111) salienta que "[...] não há possibilidade de individualização sem socialização, assim como não há socialização possível sem individualização [...]". Dessa forma, as vozes, as interações, o dito e o não-dito e o encontro com o outro num espaço de diálogo podem favorecer a formação dos professores e a ressignificação de sua prática.

Bakhtin (2000) afirma que é possível abrir novos horizontes e criar novos caminhos metodológicos, de análise, de estudo a partir da linguagem e do contexto vivenciado por professores-formadores num ambiente virtual de aprendizagem. Destarte, o uso didáticopedagógico das TIC pode possibilitar, entre os professores, diferentes práticas comunicacionais na perspectiva do multiletramento, com vistas a romper com processos didáticos pautados apenas em textos escritos, na busca da utilização de diferentes semioses (linguística, espacial, visual, sonora) entrelaçadas umas às outras a fim de que o conhecimento seja pensado de forma mais interativa.

Lave e Wenger (1991), quando se referem à aprendizagem em um processo de formação continuada, tencionam "o fato de que as instituições sejam as únicas capacitadas para ensinar, ou que a aprendizagem se dêem de modo essencial ou fundamental nas instituições acadêmicas". Contestam o modo comum de se entender o que é aprender e o que é compreender. Para os autores, não é somente nessas instituições que se processa a aprendizagem, e afirmam que:

A aprendizagem envolve a pessoa toda, como um todo, de modo holístico, considerando o sujeito da aprendizagem como uma totalidade, sua atividade em seu mundo como constitutivos do ato de aprender. Não se pode isolar o indivíduo que aprende de seu entorno social. A aprendizagem é uma atividade social (1991, p. 55).

Wenger (1998 apud MOSER, 2010), ressalta a CoP independente do aspecto virtual, como possibilidade de formação continuada virtual e pontua elementos da tecnologia de informação necessários para uma CoP que possa atender aos participantes como: a) uma homepage que descreva seu domínio e atividades; b) facilidades para enviar perguntas para a comunidade ou para um subgrupo da comunidade; c) um local com informações dos membros sobre suas áreas de expertise no domínio; d) um espaço compartilhado para colaboração, discussão e encontros eletrônicos; e) um repositório de documentos para a base de conhecimento; f) um mecanismo de busca suficientemente eficaz para recuperar itens da base de conhecimento; g) ferramentas para gerenciar a comunidade; h) facilidades para criar subcomunidades, subgrupos e equipes de projeto.

Vygotsky (1989) ressalta que a interação entre os pares, promove o desenvolvimento, e a instrução compartilhada e transmitida em determinada área pode transformar e reorganizar as outras áreas do pensamento. 
Nessa concepção, a transmissão cultural se dá via processos de mediação entre sujeito e cultura, portanto as situações de ensino-aprendizagem configuram-se como áreas de desenvolvimento, as chamadas zonas de desenvolvimento proximal - ZDP (VYGOTSKY, 1989). Portanto, o desenvolvimento humano marcado pela dimensão histórico-cultural ocorre em dois níveis: o nível de desenvolvimento real (aquilo que se é capaz de realizar sozinho) e o nível de desenvolvimento potencial (aquele no qual o sujeito é capaz com o suporte de outro mais experiente).

Em se tratando da formação continuada de professores, pode-se inferir a importância das interações e das mediações na construção do conhecimento. Nesse sentido, a CoP Virtual representa a máquina cooperativa por meio da qual os agentes estabelecem parcerias para a pesquisa e o aviamento de experiências de aprendizagem, com vistas a tornar o processo de ensino e de aprendizagem mais dinâmico.

As formulações de Wenger (1991) e Moser (2010) são significativas para a formação docente em serviço ao oportunizar a reflexão sobre suas práticas pedagógicas no contexto do Ensino Superior, por se tratar de um processo formativo que inclui a valorização da experiência dos docentes, assim como o repertório de conhecimento já construído.

Para exemplificar uma CoP, recorrem-se a duas experiências didático-pedagógicas realizadas pelo Projeto Integrado em Gestão da Informação (PIGI) do curso de Gestão da Informação da Universidade Federal do Paraná, realizadas entre os anos 2004 e 2005 e analisadas pelas autoras Freitas, at al. (2007). Em 2004, em uma experiência inicial, os professores ministrantes de duas disciplinas do referido curso montaram um grupo de estudo virtual. Utilizaram os trabalhos finais de suas disciplinas para discutirem sobre o nível de apropriação dos conteúdos pelos alunos, debatendo e avaliando práticas docentes e as demandas das disciplinas. Tais ponderações contribuíram para implantar novas formas de abordagens pedagógicas.

Em 2005, com professores que já haviam participado da primeira experiência e englobando um número maior de docentes do mesmo curso e alunos, totalizando cinco disciplinas envolvidas e alunos, passaram a trocar ideias, experiências e materiais de aprofundamento teórico com propostas de ações a serem desenvolvidas pelos alunos. De acordo com as autoras, nessa segunda experiência agregou-se ao estudo dos conteúdos "uma compreensão mais consistente e estruturada dos processos, produtos, sistemas, serviços relativos à gestão da informação" (FREITAS et al. 2007, p. 8) colaborando com a formação dos docentes e alteração de práticas pedagógicas melhorando a qualidade do ensino ofertado e a participação acadêmica.

Tais experiências via CoP promoveram a aproximação entre docentes e alunos do curso, troca de experiências pedagógicas; aprofundamento teórico; conhecimento dos posicionamentos dos professores participantes e o estímulo a uma formação docente continuada em serviço que possibilita a participação de diversas pessoas desconsiderando o espaço geográfico e temporal. Essas experiências realizadas pelo Projeto PIGI são exemplos de efetivação de uma CoP considerados essenciais para que os docentes nas universidades possam repensar suas ações e não se sintam isolados com suas disciplinas e em seus departamentos.

Diante dessas experiências via CoP, verifica-se sua preponderância em relação à formação continuada presencial, pois aproxima e promove tanto a aprendizagem individual quanto coletiva mediante a aprendizagem colaborativa. No entanto, o grande desafio ainda consiste em fazer emergir e dar crédito ao Ambiente Virtual de Aprendizagem (AVA) como suporte possível de formação continuada para os profissionais do Ensino Superior e ainda com possibilidade de ser estendido a qualquer nível de ensino ou segmento da sociedade. 


\section{DISCUSSÃO}

Um novo formato de formação continuada virtual que vem se propagando entre os profissionais da educação em exercício são as Comunidades de Prática (CoP) virtuais. Wenger et al. (2002) assim definem as CoP:

Comunidades de prática são grupos de pessoas que compartilham uma preocupação, um conjunto de problemas, ou uma paixão a respeito de algum tópico, e que aprofundam seu conhecimento e expertise nesta área interagindo numa forma permanente (p. 4).

Moser (2010) enuncia que o termo "Comunidades de Prática" foi estabelecido por Lave e Wenger (1991) ao apresentarem as proposições da Teoria da Cognição Situada (TCS), na qual a aprendizagem é uma atividade que não pode ser separada do restante de nossas vidas, porque é intrínseca à natureza humana. Ainda para os autores, o processo de interação e a dinâmica que acontece entre os membros participantes de uma comunidade, promovem a realização de novos conhecimentos, estruturando e fortalecendo os aspectos basilares da aprendizagem e da vida social.

Assim, para ser um participante das CoP, se faz necessário primeiramente o desejo de aprender num processo colaborativo; haver uma prática em um domínio comum e a vontade do seu compartilhamento no sentido de uma aprendizagem social na perspectiva sócio-interacionista decorrente da Teoria Sociocultural de Vygotsky (1989).

Vygotsky (1989) caracteriza a aprendizagem e o desenvolvimento como processos mediados pelas diversas perspectivas e posicionamentos entre participação central e periférica à medida que os participantes vão se inserindo nas discussões e atividades propostas nas CoP.

Assim, apresenta-se o uso das CoP como uma possibilidade viável de interação pedagógica e social entre os docentes em dada instituição, visto que a reunião de diversos docentes, em um mesmo lugar e horário, muitas vezes torna-se uma tarefa que é impedida pelos compromissos de cada um.

Tapscott (1999) relata que os estudantes têm apresentando novas formas de aproximação com o conhecimento, contudo nas instituições de Ensino Superior os professores, muitas vezes, recorrem somente às aulas expositivas, à lousa e ao giz, persistindo em um tradicionalismo decorrente da falta de conhecimento teórico e habilidades técnicas referentes, por exemplo, ao uso das tecnologias.

Para Moser (2010), se faz necessário que os docentes do Ensino Superior considerem essa nova geração de acadêmicos diferentes daqueles descritos e considerados pelos teóricos clássicos. A concepção e perspectiva socioconstrucionista ${ }^{1}$ (ALMEIDA, 2000), pautada pela reflexão na práxis, auxilia na medida em que, evidencia o papel do mediador no processo de aprendizagem, requerendo do professor o máximo de contextualização inter e transdisciplinar, domínio teórico e técnico referentes às tecnologias educativas para a promoção de novas práticas pedagógicas que venham a atender às necessidades dessa geração.

Nesse âmbito, uma prática de formação continuada virtual por meio das CoP no contexto do Ensino Superior, que leve à promoção da reflexão, autoavaliação, sanando dúvidas e angústias, contribuiria para a formação de educadores reflexivos, o que vai ao encontro da perspectiva de Schön (1992, p.112), para a qual "o pensamento prático do professor não pode ser ensinado, mas pode ser aprendido. Aprende-se fazendo e refletindo na e sobre a ação". Nessa perspectiva, defende-se aqui uma formação inicial que propicie experiências com o uso das TIC que poderá

\footnotetext{
${ }^{1} \mathrm{O}$ construcionismo consiste na construção do conhecimento por meio do computador. O aluno é o construtor do seu conhecimento, pois, ao interagir com as tecnologias, ele manipula conceitos e desenvolve habilidades e a ênfase está aprendizagem e não no ensino; na construção do conhecimento e não na instrução (MENDES, 2009, p. 28).
} 
servir de exemplo a ser reproduzido em futuras práticas, mas pontua-se que essa possibilidade dependerá das práticas exercidas pelos docentes das IES.

\section{CONCLUSÃO}

Considera-se que as CoP constituem uma abordagem bastante interessante para a formação continuada de docentes das instituições do Ensino Superior. Isso porque as CoP, além de utilizarem o suporte virtual e ampliar as possibilidades de encontros de aprendizagem entre os professores, colaboram para que o alcance quantitativo e qualitativo seja mais expressivo em relação aos cursos formativos presenciais contribuído para a adoção de novas práticas pedagógicas inclusive as que envolvem as TIC.

As relações sociais e sensações de pertencimento são constantes nas CoP desde que esses aspectos sejam evidenciados e sejam percebidos como centrais nas relações de aprendizagem. A argumentação a partir do suporte teórico aqui apresentado, referentes as relações de ensino e aprendizagem que ocorrerem por meio de uma construção social, contribuem para dar respaldo e fortalecer as CoP como uma ferramenta que possibilita autonomia, troca de experiência, respeito mútuo, organização do trabalho docente e um contato mais produtivo com as TIC, compreendendo assim as CoP como uma importante rede social além das já estabelecidas e popularizadas na atualidade.

\section{REFERÊNCIAS}

ALMEIDA, M. E. Bianconcini. de. Informática e formação de professores. Brasília: Ministério da Educação, 2000. v. 2. 191 p.

BAKHTIN, M. Estética da Criação Verbal. São Paulo: Martins Fontes, 2000.

BRASIL. Lei $n^{\circ}$ 9.394, de 20 de dezembro de 1996. Estabelece as Diretrizes e Bases da Educação Nacional. Brasília, DF: 1996.

FRANCO, M. A. S. Pesquisa-Ação e Prática Docente: articulações possíveis. In: PIMENTA, S.G; FRANCO, M.A. (Org). Pesquisa em Educação: possibilidades investigativas/formativas da pesquisaação. São Paulo: Ed. Loyola, 2008. P. 103-138.

FREITAS, M. T. de A. Bakhtin e Vygotsky: um encontro possível. In: BRAIT, B. (Org.). Bakhtin, dialogismo e construção de sentidos. Campinas: Unicamp, 1997.

FREITAS. M. C. D. et al. Comunidades de Aprendizagem: experiência acadêmica no projeto integrado em gestão da informação. Revista Informação \& Informação. v.12, no 1, jan/fev. 2007.

LAVE, J.; WENGER, E. Situated Learning: Legitimate peripheral participation. Cambridge:

Cambridge University Press, 1991, https://doi.org/10.1017/CBO9780511815355.

MOSER, A. Formação Docente em comunidades de prática. Revista Intersaberes, Curitiba, a. 5, n.10, p. 210-244, jul./dez. 2010.

SCHÖN, D. La formación de profesionales reflexivos. Hacia un nuevo desafio de la enseñanza y el aprendizaje en las profesiones. Barcelona, 1992.

TAPSCOTT, D. Geração Digital. São Paulo, Makron Books, 1999. 
VYGOTSKI. L.S. A formação social da mente. Tradução José Cipolla Neto; Luiz Silveira Barreto; Solange Afeche. São Paulo: Martins Fontes, 1989.

WENGER, E. MCDERMOTT, R. SNYDER, W. Cultivating Communities of Practice. U.S.A.: Harvard University Press, 2002.

. Communities for practice, learning, meaning, and identity. USA.: Cambridge University Press. 1998. 